\title{
MECANISMOS MOLECULARES DE RESISTENCIA A QUINOLONAS EN CEPAS DE Escherichia coli UROPATÓGENAS
}

\author{
Molecular mechanisms of quinolone-resistant uropathogenic Escherichia coli strains
}

Ana M. Horna-Ruíz, Amparo I. Zavaleta, Liz Corahua, Víctor Izaguirre

Laboratorio de Biología Molecular, Facultad de Farmacia y Bioquímica,Universidad Nacional Mayor de San Marcos

\section{RESUMEN}

El empleo de quinolonas para el tratamiento de infecciones del tracto urinario (ITU) se ha incrementado notablemente, hecho que ha conllevado a la aparición de cepas resistentes. El objetivo del estudio fue determinar los perfiles y mecanismos moleculares por los que las cepas de $E$. coli uropatógenas resistentes a quinolonas sobreviven a dichos antibióticos. Para ello, se utilizaron 3 cepas de $E$. coli uropatógenas sensibles y 58 cepas resistentes. En cuanto a la sensibilidad antimicrobiana, se utilizó el método de difusión en disco para ácido nalidixico (W), ciprofloxacino (Cip), levofloxacino (Lvx), norfloxacino (Nfx) y moxifloxacino (Mxf). Las pruebas moleculares consistieron en la reacción en cadena de la polimerasa (PCR), polimorfismo en longitud de los fragmentos de restricción (RFLP) y secuenciación del gen gyr $A$. Para el análisis de datos se utilizaron los programas Excel, Blastn y ClustalX. Las cepas de E. coli uropatógenas presentaron dos perfiles mayoritarios: resistencia a W 25,90\% y cepas resistentes a WCipNorLvxMxf $43,10 \%$. Mediante RFLP-PCR del gen gyr $A$, se determinó que $50(86,20 \%)$ cepas presentaron una mutación puntual en el codón que cambió el aminoácido Ser 83 por Leu en la ADN girasa A; mientras que cuatro cepas no presentaron esta mutación. Con el análisis de las secuencias nucleotídicas del gen gyr $A$ de 26 cepas, se confirmaron los perfiles de restricción; además, se detectó un cambio en el codón de Asp 87 a Asn en 22 de las cepas analizadas. Las cepas de $E$. coli uropatógenas resistentes a WCipNorLvxMxf representaron el principal perfil de resistencia a quinolonas. Asimismo, la mayoría de cepas contienen una mutación en la ADN girasa A que cambia de Ser 83 a Leu.

Palabras clave: Escherichia coli uropatógena, quinolonas, resistencia antimicrobiana, ADN girasa A, gen gyr $A$.

\section{SUMMARY}

The use of quinolones for the treatment of urinary tract infections (UTI) has increased dramatically, a fact that has led to the emergence of resistant strains of pathogen. The aim of the study was to determine the profiles and molecular mechanisms of quinoloneresistant uropathogenic Escherichia coli strains. For this, 3 sensitive strains of E. coli uropathogenic and 58 quinolone-resistant strains were used in the antimicrobial sensitivity with the disk diffusion method for nalidixic acid (W), ciprofloxacin (Cip), levofloxacin (Lvx), norfloxacin (Nfx) and moxifloxacin (Mxf). For molecular tests were used polymerase chain reaction (PCR), restriction fragments length polymorphism (RFLP) and sequencing of $g y r A$ gene. Excel, Blastn and ClustalX programs were used for data analysis. Uropathogenic $E$. coli strains showed two major patterns: $25,90 \%$ resisted $W$ and 43,10\% resisted WCipNorLvxMxf. RFLP-PCR of $g y r A$ gene showed that $50(86,20 \%)$ strains had a point mutation in codon 83 wich changed Ser by Leu in the DNA gyrase A, while four strains did not have this mutation. With the analysis of nucleotide sequences of gyr $A$ gene from 26 strains were confirmed restriction patterns; besides, 22 strains a mutation changed Asp 87 to Asn. Uropathogenic $E$. coli strains resistant to WCipNorLvxMxf represented the main pattern of quinolone resistance. Also, most strains contain a mutation in the DNA gyrase A changing Ser 83 by Leu.

Keywords: Uropathogenic Escherichia coli, quinolones, antimicrobial resistance, DNA girase A, gene gyr A.

\section{INTRODUCCIÓN}

as infecciones del tracto urinario (ITU) son frecuentemente diagnosticadas en pacientes ambulatorios y hospitalizados, se estima que entre el 80 a $90 \%$ de estas son de origen bacteriano, algunas veces sin presencia de síntomas. Por ello, las ITU constituyen un serio problema de salud que afecta a millones de personas cada año, siendo la segunda causa de infección más frecuente en humanos. La mayoría de mujeres tiene al menos una ITU durante su vida y es común en gestantes; así, la proporción de ITU entre mujeres y hombres jóvenes es de 30: ${ }^{(1-5)}$.
E. coli uropatógena (UPEC), es uno de los agentes causales más frecuentes de las ITU, se le ha descrito resistencia crecienteaampicilina, amoxicilinay cefalosporinasdeprimera y segunda generación. Ante esta situación, se recomienda el uso de quinolonas, siendo ciprofloxacino y norfloxacino los más usados por prescripción médica y automedicación. Sin embargo, el uso de quinolonas como terapia de primera línea para el tratamiento de ITU no complicada se debería evitar para disminuir la resistencia ${ }^{(6)}$.

En bacterias Gram negativas como $E$. coli, el blanco o sitio de acción de las quinolonas es la ADN girasa, que 
contiene dos subunidades alfa y dos beta, y es codificada por los genes $g y r A$ y $B$, respectivamente. Mutaciones puntuales en los codones del gen gyr $A$ que codifican los aminoácidos Ser 83y Asp 87 de la ADN girasa A en la Región Determinantede Resistencia a Quinolonas (QRDR), es lavía más común de resistencia a este grupo de antimicrobianos. Diversos estudios describen a las mutaciones puntuales en la región QRDR del gen gyr $A$ como responsables de la alta resistencia, principalmente a fluoroquinolonas. Otros mecanismos de resistencia son la disminución del número de porinas en la membranay un sistema de eflujo de la droga del citosol hacia el espacio extracelular ${ }^{(7,8)}$.

Elincrementoderesistenciaadiversosantimicrobianos, y en particular a quinolonas, se traduce en un deterioro de la calidad del tratamiento afectando no sólo al paciente, sino que, al reducir la disponibilidad de antimicrobianos, afectan su eficacia y por tanto el tratamiento de las infecciones en el futuro. En Perú, la resistencia a ciprofloxacino en pacientes ambulatorios con ITU varía entre 14 a $25 \%$, y en pacientes hospitalizados es de $31 \%{ }^{(9)}$. En consecuencia, el objetivo del estudio fue determinar las mutaciones frecuentes en el gen gyr $A$ en cepas de $E$. coli uropatógenas resistentes a quinolonas mediante la reacción en cadena de la polimerasa, el polimorfismo en longitud de los fragmentos de restricción y la secuenciación del gen gyr $A$.

\section{MATERIALES Y MÉTODOS}

\section{Cepas de $E$. coli uropatógenas}

Se utilizaron cepas de Escherichia coli uropatógenas, provenientes de pacientes mujeres procedentes de instituciones de salud de Lima Norte, las cuales fueron recolectadas entre el 2001 y 2007. De las cepas empleadas, 58 presentaron resistencia a una o más quinolonas y tres fueron sensibles. E. coli ATCC 8739 fue utilizada como indicadora de sensibilidad a estas drogas.

\section{Prueba de sensibilidad a quinolonas}

Se realizó según la prueba de difusión en disco de Kirby-Bauer. Previamente, se reactivaron las cepas en caldo tripticasa de soyaa $37^{\circ} \mathrm{C}$ durante $18 \mathrm{~h}$. Luego se cultivaron en agar tripticasa de soya (TSA) en las condiciones antes descritas, siendo la dilución del inóculo equivalente a o,5 en la escala de McFarland; posteriormente, usando un hisopo estéril, se sembró sobre la placa de agar Mueller Hinton. Después, los discos de ácido nalidíxico $30 \mu \mathrm{g}$, norfloxacino $10 \mu \mathrm{g}$, ciprofloxacino $5 \mu \mathrm{g}$, levofloxacino $5 \mu \mathrm{g}$, moxifloxacino $5 \mu \mathrm{g}$, provenientes de EMV (Chile), se colocaron sobre el agar sembrado e incubaron a $37^{\circ} \mathrm{C}$ durante $24 \mathrm{~h}$. Los tamaños de los halos de inhibición fueron medidos con una regla e interpretados según las tablas del CLSI y se clasificaron como sensibles o resistentes a los antimicrobianos que se usaron en este estudio ${ }^{(10)}$.

\section{Extracción de ADN genómico}

Las cepas de $E$. coli uropatógenas fueron cultivadas en caldo Luria Bertani a $37^{\circ} \mathrm{C}$ hasta alcanzar la fase exponencial, aproximadamente a las $12 \mathrm{~h}$. Después, el cultivo se centrifugó a $6000 \mathrm{rpm}$ por $10 \mathrm{~min}$, el precipitado celular se resuspendió en $300 \mu \mathrm{L}$ de buffer de lisis pH 8,o, se añadieron $15 \mu \mathrm{L}$ de SDS $20 \%$ y $5 \mu \mathrm{L}$ de proteínasa $\mathrm{K}$, se incubó a $55^{\circ} \mathrm{C}$ por $4 \mathrm{~h}$. Luego, se añadieron $300 \mu \mathrm{L}$ de la mezcla fenol:cloroformo (1:1), se homogeneizó y centrifugó por 5 min a 9000 rpm, se separaron $250 \mu \mathrm{L}$ de la fase acuosa y se añadió igual volumen de cloroformo. A $200 \mu \mathrm{L}$ de la fase acuosa se añadió acetato de sodio $3 \mathrm{M}$ e isopropanol, se centrifugó a $9000 \mathrm{rpm}$ durante $5 \mathrm{~min}$, y finalmente el ADN se disolvió en $30 \mu \mathrm{L}$ de buffer TE. Para verificar la pureza y la concentración del ADN se realizó una electroforesis utilizando geles de agarosa $1 \%$ con TAE $1 \mathrm{X}$ a $80 \mathrm{~V}$ y el marcador de peso molecular ADN del fago Lambda/ Hind III. El gel de agarosa se coloreó con bromuro de etidio y se visualizó en un transiluminador de luz UV.

\section{Reacción en Cadena de la Polimerasa (PCR)}

El volumen final de la reacción fue de $25 \mu \mathrm{L}$ conteniendo buffer $1 \mathrm{X}, \mathrm{MgCl}_{2} 1,5 \mathrm{mM}$, deoxinucleótidos trifosfatos $200 \mu \mathrm{M}$, Taq ADN polimerasa $1 \mathrm{U}$, iniciadores 10 $\mu$ Mdecadauno (GyrAF-TACACCGGTCAACATTGAGG-3' y Gyr AR 5'TTAATGATTGCCGCCGTCGG-3'), ADN genómico 50 yg. La amplificación del ADN fue realizado en el termociclador Perkin Elmer 240o. Las condiciones de reacción fueron las siguientes: desnaturalización inicial a $94^{\circ} \mathrm{C}$ por $5 \mathrm{~min}$, seguido de 35 ciclos (desnaturalización $94^{\circ} \mathrm{C}$ por 30 s, hibridación a $62^{\circ} \mathrm{C}$ por 30 sy polimerización a $72^{\circ} \mathrm{C}$ por $30 \mathrm{~s}$ ); y 1 ciclo final de polimerización a $72^{\circ} \mathrm{C}$ por 5 min. Se utilizó como control negativo la mezcla de reacción sin $\mathrm{ADN}$ y como control positivo $\mathrm{ADN}$ de E. coli ATCC 8739. Los productos de PCR se separaron por electroforesis en gel de agarosa $1,5 \%$ utilizando buffer TBE 1 X a $80 \mathrm{~V}$, usando el marcador de peso molecular Hyperladder II (Bioline Inc. USA).

\section{Digestión de los productos amplificados}

A un microgramo de ADN del gen gyr $A$ amplificado, se añadió $\operatorname{Hinf}$ I 5 U siguiendo las instrucciones del fabricante. Los productos de la digestión se separaron por electroforesis en gel de agarosa 3:1 HRB 3,5\% (Amresco Inc, USA) utilizando buffer TBE o,5 X a 8o V, se utilizó el marcador de peso 
molecular "Hiperladder II" (Bioline Inc. USA). Los geles se tiñeron con bromuro de etidio y se fotografiaron en un transiluminador de luz ultravioleta a $305 \mathrm{gm}$.

\section{Secuenciación del gen gyr $A$}

La zona del gen gyr $A$ amplificado conteniendo la región QRDR fue sencuenciada para determinar la mutación más frecuente asociada con la resistencia a quinolonas. La secuenciación se realizó en el analizador de ADN ABI Prism 3100 (Applied Biosystems, USA) del Instituto de Medicina Tropical "Alexander von Humbodlt" de la Universidad Peruana Cayetano Heredia.

\section{Análisis de datos}

Se esquematizaron los perfiles de restricción del gen gyr $A$, alineando cada banda y tomando como referencia los pesos moleculares del marcador Hiperladder II. Los perfiles de ADN de las cepas resistentes a quinolonas se compararon con el perfil de las cepas sensibles. Los datos se analizaron utilizandoel programa Excel. Paraelanálisisdelassecuencias del gen $g y r A$ de las cepas de $E$. coli uropatógenas se utilizaron sistemáticamente dos programas bioinformáticos de libre acceso: BLASTn, que permite encontrar regiones de semejanza local entre diversas secuencias de nucleotídos y aminoácidos; CLUSTALX 2.o.9, que permite alinear varias secuencias de nucleótidos y aminoácidos a identificar; y Bioedit, que facilita la edición de las secuencias.

\section{RESULTADOS}

\section{Análisis de sensibilidad de las cepas de $E$. coli uropatógenas}

En este estudio se utilizaron 61 cepas UPEC, 3 sensibles y 58 resistentes a quinolonas (W, Cip, Nor, Lev, Mfx), determinadas utilizando el método de difusión de Kirby Bauer. En la tabla 1 se muestran los perfiles de sensibilidad de dichas cepas.

En la figura 1 se observa la distribución de los fenotipos de resistencia a quinolonas, los más frecuentes son $15(25,86 \%)$ cepas resistentes a W y 25 (43,10\%) cepas resistentes a cinco antimicrobianos (WCipNorLvxMxF). Las otras cepas de $E$. coli presentaron fenotipos de resistencia a otras combinaciones de antimicrobianos.

\section{RFLP-PCR del gen $g y r A$ en cepas de $E$. coli uropatógenas}

Seamplificópartedelgen gyrAquecontienelaregiónde resistencia a quinolonas (QRDR), donde están ubicados los cambios nucleotídicos responsables de dicha característica; el producto amplificado midió $648 \mathrm{pb}$. El gen gyr $A$ cortado con la enzima Hinfl generó tres fragmentos de 99, 221 y 328 pb en las cepas de $E$. coli sensibles y, en las cepas resistentes, el fragmento de $\mathrm{ADN}$ midió aproximadamente $324 \mathrm{pb}$ (figura 2). Cabe señalar que en esta mancha comigraron los fragmentos de 320 y $328 \mathrm{pb}$, que no se separaron por no usar geles de agarosa de bajo punto de fusión y alta resolución. Por otro lado, se puede notar que las cepas LBM 24, 77, 98 y 99, resistentes a quinolonas, presentaron perfiles de restricción similares a las sensibles (tabla 1), lo cual indicaría que los mecanismos de resistencia de estas cuatro cepas está a nivel de transporte o eflujo del antimicrobiano.

\section{Análisis de secuencias nucleotídicas del gen $g y r A$}

Las 26 secuencias nucleotídicas del gen $g y r A$ de cepas UPEC, se alinearon y editaron con los programas ClustralX y BioEdit. Después de la edición se obtuvieron 270 nucleótidos ubicados entre las posiciones 151 a 420 del gen gyr $A$, correspondiendo a 90 aminoácidos traducidos de las posiciones 51 a 140 de la ADN girasa de $E$. coli. Dentro de esta secuencia está ubicada la región determinante de resistencia a quinolonas (QRDR), entre las posiciones $67 \mathrm{a}$ 106, esta zona ha sido subrayada en la figura 3.

Para el análisis se utilizaron 39 secuencias del gen $g y r$ $A$ de $E$. coli obtenidas del GenBank. La cepa $E$. coli ATCC 8739 , es sensible a quinolonas y no presenta cambios en las posiciones 83 y 87 de la región QRDR. En la figura 3 se observa el grado de conservación del gen $g y r A$, cuya proteína participa en la replicación del ADN genómico. El cambio de $C$ por $\mathrm{T}$ en el nucleótido 98 del gen $g y r A$ originó la modificación de Ser 83 por Leu (figura 3).

De las 26 cepas UPEC resistentes a quinolonas, tres no presentaron ninguna mutación que conllevea cambios en las posiciones en estas posiciones aminoacídicas; sin embargo, las 23 cepas restantes, presentaron los dos cambios de Ser 83 por Leu y Asp 87 por Asn, a excepción de la cepa LBMig, que cambio Asp 87 por Tyr (figura 3 ).

\section{DISCUSIÓN}

Lasquinolonas, especialmentelas fluoroquinolonas, son agentes antibacterianos de amplio espectro usados en el tratamiento de infecciones adquiridas en la comunidad y en hospitales. La alta potencia, actividad y relativa tolerancia que ostentan estos fármacos, han conllevado a su uso frecuente en el tratamiento de infecciones del tracto urinario y al incremento de cepas UPEC resistentes a estos antimicrobianos ${ }^{(11-13)}$.

Las 58 cepas UPEC estudiadas mostraron diversos perfiles de resistencia, el más frecuente - presentado por 25 de ellas - fue a cinco quinolonas (W, Cip, Lvx, Nor, Mxf). Además, se encontraron 15 cepas resistentes a ácido nalidíxico, las cuales llegarán a ser resistentes a 
Tabla 1. Cepas de E. coli uropatógenas con perfiles de resistencia a quinolonas.

\begin{tabular}{|c|c|c|c|c|c|c|c|}
\hline $\begin{array}{c}\mathrm{N}^{\circ} \\
\text { Cepa }\end{array}$ & Código & $\begin{array}{c}\text { Ácido } \\
\text { nalidíxico }\end{array}$ & Ciprofloxacino & Norfloxacino & Levofloxacino & Moxifloxacino & RFLP-PCR \\
\hline 1 & LBM 1 & $\mathrm{~S}$ & $S$ & $\mathrm{~S}$ & $\mathrm{~S}$ & $\mathrm{~S}$ & + \\
\hline 2 & LBM2 & $\mathrm{R}$ & $\mathrm{R}$ & S & S & S & - \\
\hline 3 & LBM4 & $\mathrm{R}$ & $\mathrm{R}$ & $\mathrm{R}$ & $\mathrm{R}$ & $\mathrm{R}$ & - \\
\hline 4 & LBM5 & $\mathrm{R}$ & S & S & S & $\mathrm{S}$ & - \\
\hline 5 & LBM6 & $\mathrm{R}$ & S & S & S & S & - \\
\hline 6 & LBM8 & $\mathrm{R}$ & S & S & S & S & - \\
\hline 7 & LBM10 & $\mathrm{R}$ & $\mathrm{R}$ & $\mathrm{R}$ & $\mathrm{R}$ & $\mathrm{R}$ & - \\
\hline 8 & LBM12 & $\mathrm{R}$ & $\mathrm{R}$ & $\mathrm{R}$ & S & $\mathrm{R}$ & - \\
\hline 9 & LBM18 & $\mathrm{R}$ & $\mathrm{R}$ & $\mathrm{R}$ & $\mathrm{R}$ & $\mathrm{R}$ & - \\
\hline 10 & LBM19 & $\mathrm{R}$ & $\mathrm{R}$ & $\mathrm{R}$ & $\mathrm{R}$ & $\mathrm{R}$ & - \\
\hline 11 & LBM21 & $\mathrm{R}$ & $\mathrm{S}$ & $\mathrm{S}$ & S & $\mathrm{S}$ & - \\
\hline 12 & LBM22 & $\mathrm{R}$ & $\mathrm{R}$ & $\mathrm{R}$ & $\mathrm{R}$ & $\mathrm{R}$ & - \\
\hline 13 & LBM24 & S & $\mathrm{R}$ & S & $\mathrm{R}$ & $\mathrm{R}$ & + \\
\hline 14 & LBM25 & $\mathrm{R}$ & $\mathrm{S}$ & $\mathrm{S}$ & $\mathrm{S}$ & $\mathrm{S}$ & - \\
\hline 15 & LBM26 & $\mathrm{R}$ & $\mathrm{R}$ & $\mathrm{R}$ & $\mathrm{R}$ & $\mathrm{R}$ & - \\
\hline 16 & LBM28 & $\mathrm{R}$ & $\mathrm{S}$ & S & $\mathrm{S}$ & $\mathrm{S}$ & - \\
\hline 17 & LBM29 & $\mathrm{R}$ & S & S & S & $\mathrm{S}$ & - \\
\hline 18 & LBM30 & $\mathrm{R}$ & $\mathrm{R}$ & S & S & S & - \\
\hline 19 & LBM32 & $\mathrm{R}$ & $\mathrm{R}$ & $\mathrm{R}$ & $\mathrm{R}$ & $\mathrm{R}$ & - \\
\hline 20 & LBM33 & $\mathrm{R}$ & $\mathrm{R}$ & S & S & $\mathrm{R}$ & - \\
\hline 21 & LBM34 & $\mathrm{R}$ & $\mathrm{S}$ & $\mathrm{R}$ & S & $\mathrm{R}$ & - \\
\hline 22 & LBM36 & $\mathrm{R}$ & $\mathrm{R}$ & $\mathrm{R}$ & $\mathrm{R}$ & $\mathrm{R}$ & - \\
\hline 23 & LBM39 & $\mathrm{R}$ & $\mathrm{R}$ & $\mathrm{R}$ & $\mathrm{R}$ & $\mathrm{R}$ & - \\
\hline 24 & LBM40 & S & $\mathrm{S}$ & $\mathrm{S}$ & S & S & + \\
\hline 25 & LBM41 & $\mathrm{R}$ & $\mathrm{R}$ & $\mathrm{R}$ & $\mathrm{R}$ & $\mathrm{R}$ & - \\
\hline 26 & LBM46 & $\mathrm{R}$ & $\mathrm{R}$ & $\mathrm{R}$ & $\mathrm{R}$ & $\mathrm{R}$ & - \\
\hline 27 & LBM47 & S & $\mathrm{R}$ & S & $\mathrm{R}$ & S & - \\
\hline 28 & LBM50 & S & $\mathrm{R}$ & S & $\mathrm{S}$ & $\mathrm{S}$ & - \\
\hline 29 & LBM54 & $\mathrm{R}$ & $\mathrm{R}$ & S & $S$ & $\mathrm{R}$ & - \\
\hline 30 & LBM55 & $\mathrm{R}$ & $\mathrm{R}$ & $\mathrm{R}$ & $\mathrm{R}$ & S & - \\
\hline 31 & LBM58 & $\mathrm{R}$ & $\mathrm{R}$ & $\mathrm{R}$ & $\mathrm{S}$ & $\mathrm{R}$ & - \\
\hline 32 & LBM63 & $\mathrm{R}$ & $\mathrm{R}$ & $\mathrm{R}$ & $\mathrm{R}$ & $\mathrm{R}$ & - \\
\hline 33 & LBM65 & S & $\mathrm{R}$ & $\mathrm{S}$ & $\mathrm{R}$ & $\mathrm{S}$ & - \\
\hline 34 & LBM68 & $\mathrm{R}$ & $\mathrm{R}$ & $\mathrm{R}$ & $\mathrm{R}$ & $\mathrm{R}$ & - \\
\hline 35 & LBM69 & $\mathrm{S}$ & S & S & S & S & + \\
\hline 36 & LBM70 & $\mathrm{R}$ & $\mathrm{R}$ & $\mathrm{R}$ & S & $\mathrm{R}$ & - \\
\hline 37 & LBM77 & $\mathrm{R}$ & $\mathrm{R}$ & $\mathrm{R}$ & $\mathrm{R}$ & $\mathrm{R}$ & + \\
\hline 38 & LBM80 & $\mathrm{R}$ & $\mathrm{R}$ & $\mathrm{R}$ & $\mathrm{R}$ & $\mathrm{R}$ & - \\
\hline 39 & LBM82 & $\mathrm{R}$ & $\mathrm{S}$ & S & $\mathrm{S}$ & $\mathrm{S}$ & - \\
\hline 40 & LBM83 & S & $\mathrm{S}$ & $\mathrm{S}$ & $\mathrm{R}$ & $\mathrm{S}$ & - \\
\hline 41 & LBM86 & $\mathrm{R}$ & $\mathrm{R}$ & $\mathrm{R}$ & $\mathrm{R}$ & $\mathrm{R}$ & - \\
\hline 42 & LBM87 & $\mathrm{R}$ & S & S & S & S & - \\
\hline 43 & LBM88 & $\mathrm{R}$ & $\mathrm{R}$ & $\mathrm{R}$ & $\mathrm{R}$ & $\mathrm{R}$ & - \\
\hline 44 & LBM90 & $\mathrm{R}$ & $\mathrm{S}$ & $\mathrm{S}$ & $\mathrm{S}$ & $\mathrm{S}$ & - \\
\hline 45 & LBM91 & $\mathrm{R}$ & $\mathrm{R}$ & $\mathrm{R}$ & S & $\mathrm{R}$ & - \\
\hline 46 & LBM92 & $\mathrm{R}$ & $\mathrm{S}$ & S & S & S & - \\
\hline 47 & LBM93 & $\mathrm{R}$ & $\mathrm{S}$ & $\mathrm{S}$ & S & $\mathrm{S}$ & - \\
\hline 48 & LBM94 & $\mathrm{R}$ & $\mathrm{R}$ & $\mathrm{R}$ & $\mathrm{R}$ & $\mathrm{R}$ & - \\
\hline 49 & LBM95 & $\mathrm{R}$ & S & S & S & S & - \\
\hline 50 & LBM97 & $\mathrm{R}$ & $\mathrm{R}$ & $\mathrm{R}$ & $\mathrm{R}$ & $\mathrm{R}$ & - \\
\hline 51 & LBM98 & $\mathrm{R}$ & $\mathrm{R}$ & $\mathrm{R}$ & $\mathrm{R}$ & $\mathrm{R}$ & + \\
\hline 52 & LBM99 & $\mathrm{R}$ & $\mathrm{R}$ & $\mathrm{R}$ & $\mathrm{R}$ & $\mathrm{R}$ & + \\
\hline 53 & LBM101 & $\mathrm{R}$ & $\mathrm{R}$ & $S$ & S & $\mathrm{R}$ & - \\
\hline 54 & LBM102 & $\mathrm{R}$ & $\mathrm{R}$ & $\mathrm{R}$ & $\mathrm{R}$ & $\mathrm{R}$ & - \\
\hline 55 & LBM106 & $\mathrm{R}$ & $\mathrm{R}$ & $\mathrm{R}$ & $\mathrm{R}$ & $\mathrm{R}$ & - \\
\hline 56 & LBM108 & $\mathrm{R}$ & $\mathrm{R}$ & S & $\mathrm{R}$ & $\mathrm{R}$ & ND \\
\hline 57 & LBM109 & $\mathrm{R}$ & $\mathrm{R}$ & $\mathrm{R}$ & $\mathrm{R}$ & $\mathrm{R}$ & - \\
\hline 58 & LBM111 & $\mathrm{R}$ & $\mathrm{R}$ & $\mathrm{R}$ & $\mathrm{S}$ & $\mathrm{R}$ & ND \\
\hline 59 & LBM112 & $\mathrm{R}$ & $\mathrm{S}$ & S & $\mathrm{S}$ & $\mathrm{S}$ & ND \\
\hline 60 & LBM113 & $\mathrm{R}$ & $\mathrm{R}$ & $\mathrm{R}$ & $\mathrm{R}$ & $\mathrm{R}$ & - \\
\hline 61 & LBM114 & $\mathrm{R}$ & $\mathrm{S}$ & S & $\mathrm{S}$ & S & ND \\
\hline
\end{tabular}

Halos de inhibición: Acido nalidíxico (W), $S \geq 19, R \leq 13$; ciprofloxacino (CIP), $S \geq 21, R \leq 15$; norfloxacino (NOR), $S \geq 17, R \leq 13$; levofloxacino (LVX), $S \geq 19, \mathrm{R} \leq 13$; moxifloxacino (MXT), $S \geq 19, \mathrm{R} \leq 15$.

$\mathrm{S}$, sensible; R, resistente; ND, no determinado; +, gen gyr $A$ amplificado cortado con $\operatorname{Hinfl}$; $\quad$-, no corto gen gyr $A$ fluoroquinolonas, dadoquea nivelgénico llevan la mutación en el gen $g y r A$, detectada mediante el polimorfismo en longitud de los fragmentos de restricción del gen $g y r$ $A$ (tabla 1, figura 2).

El uso inadecuado de los antimicrobianos, la automedicación e interrupción de la administración, etc., conlleva a cepas UPEC altamente resistentes, las cuales están circulando en la comunidad (14-16).

Similares

resultados, se obtuvieron en 40 cepas UPEC aisladas de pacientes con transplante de riñón en Galveston, Texas, donde el 6o\% de cepas fueron resistentes a fluoroquinolonas lo cual sugiere que cepas multidrogoresistentes están emergiendo en diversos lugares (16). Disminuir su avance es responsabilidad compartida entre médico y paciente, lo cual implica básicamente una correcta prescripción delosantimicrobianos por los profesionales de salud y adecuado uso por el paciente.

El cambio de nucleótidos en el codón 83 del gen 


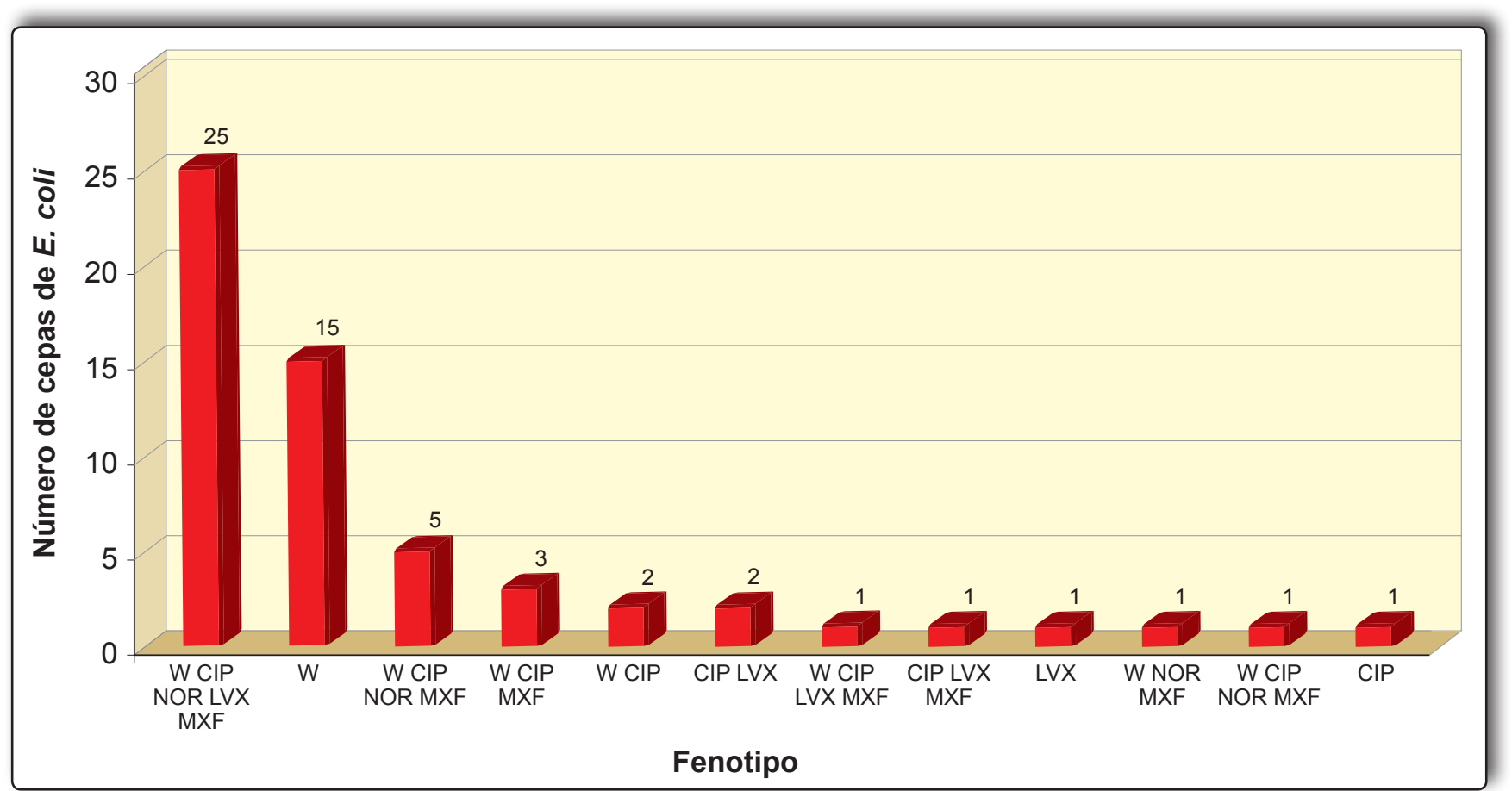

Figura 1. Número de cepas de E. coli uropatógenas según perfil de resistencia a quinolonas.

gyr $A$ de $E$. coli, está presente en $50(86,20 \%)$ cepas UPEC resistentes a quinolonas, lo que indicaría que este mecanismo es el principal. Los otros posibles mecanismos deresistencia estarían a nivel de membrana, donde existen proteínas que regulan la entrada y eflujo de los antimicrobianos en la célula procariota.

En las 23 secuencias nucleotídicas del gen gyr $A$ de cepas UPEC resistentes a quinolonas, se determinó una mutación en el codón TCG por TTC, que origina cambio de sentido de Ser 83 por Leu, este dato se correlaciona con el perfil de restricción dicho gen amplificado y cortado con Hinf I (figura 2). Además, se detectaron cambios de Asp 87 por Asn en 22 cepas que originaron doble mutación, estas cepas presentaron perfiles de resistencia a más de tres quinolonas. A la vez, se observó que el gen $g y r A$ de tres cepas resistentes no presentó mutaciones en los codones antes mencionados (figura 3), estas bacterias podrían contener otros mecanismos de resistencia tales como disminución de porinas o bombas de eflujo. Por otro lado, la resistencia a bajas concentraciones de fluoroquinolonas (MIC de o,5 a 4,o $\mu \mathrm{g}$ / $\mathrm{mL}$ ) en $E$. coli se asocia a cambios de Ser 83 por Leu; mientras la resistencia a altas concentraciones requiere doble mutación en de este que origina modificaciones en Ser 83 por Leu y Asp 87 por Gly, entre otros ${ }^{(17,18)}$.

La resistencia a quinolonas en cepas de E. coli uropatógena se debe a mutaciones secuenciales en genes que codifican las proteínas que son blanco de estos antimicrobianos, por lo que las cepas de esta bateria que presentan mutación en el gen gyr $A$, son de gran interés

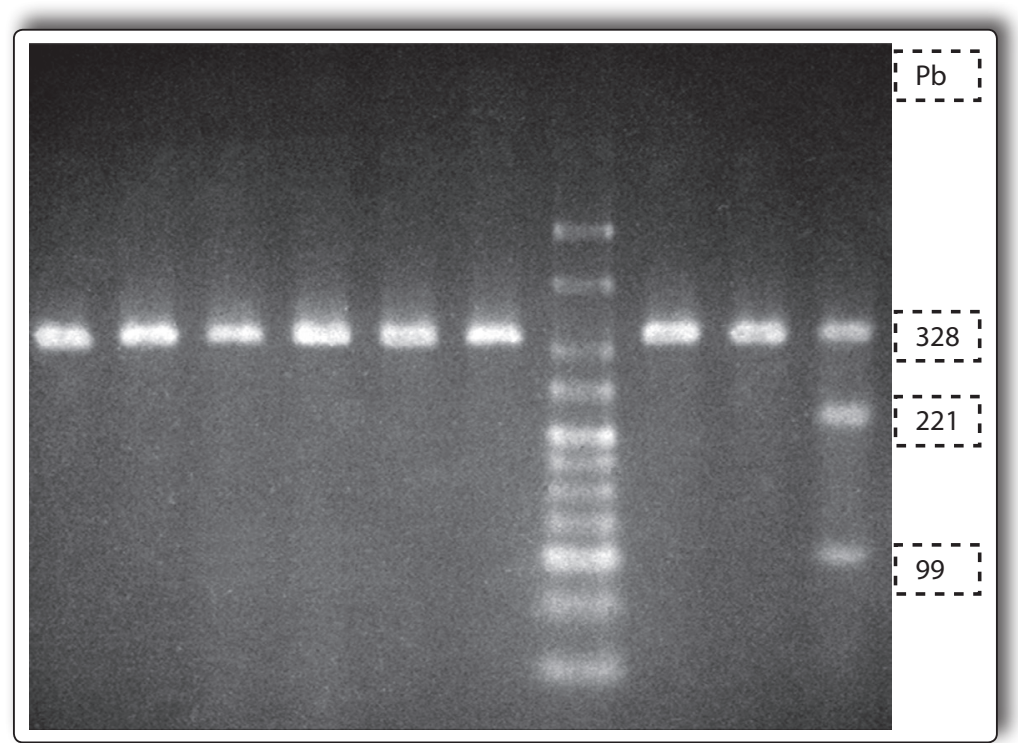

Figura 2. Gel de agarosa mostrando los perfiles de restricción del gen gyr $A$ amplificado y cortado con Hinf I de cepas de E. coli uropatógenas. Líneas 1-6, 8 y 9 resistentes a quinolonas. Línea 10, E. coli LBM40 sensible; Línea 7, Hiperladder II. 


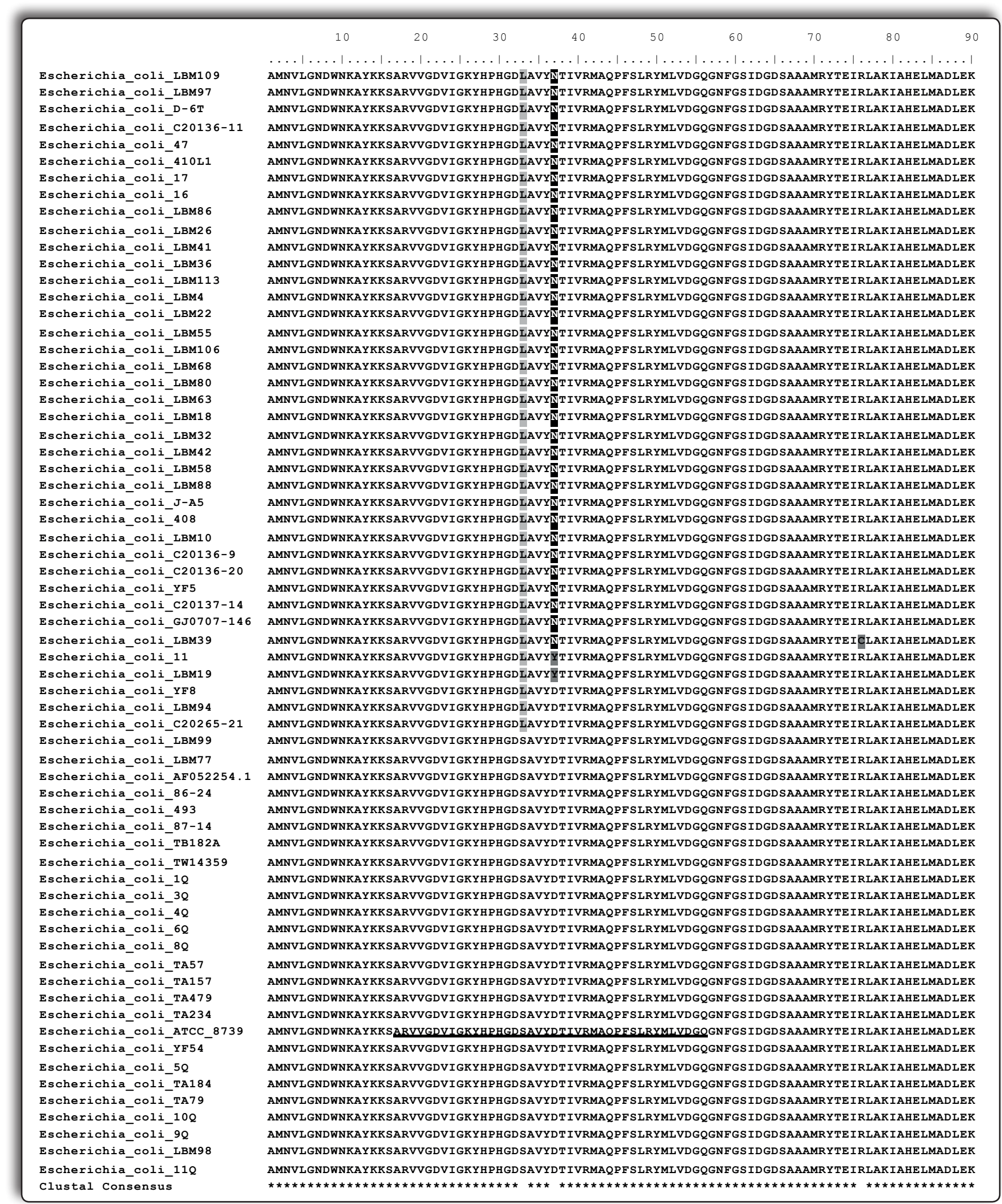

Figura 3. Alineamiento de las secuencias aminoacídicas parciales de la ADN girasa A de cepas de Escherichia coli uropatógenas resistentes a quinolonas. Los $\left(^{*}\right)$ indican los sitios conservados, la zona subrayada representa la región QRDR. 
como indicadores, ya que la presencia de una mutación aumentaría la probabilidad de adquirir otras ${ }^{(19,20)}$.

El alto porcentaje de cepas de E. coli uropatógena multi-drogoresistentes, aisladas de pacientes mujeres con infecciones del tracto urinario, motiva la realización de otros estudios con mayor número de cepas que permitan elucidar el genotipo de $E$. coli uropatógena circulante. Asimismo, se requiere una mayor concientización del médico y paciente frente a la alta resistencia antimicrobiana, no solo a quinolonas, sino a otros agentes terapéuticos, y un abordaje desde varias perspectivas tales como vigilancia permanente del consumo de antimicrobianos, notificación de los casos de resistencia y uso racional de medicamentos.

\section{CONCLUSIONES}

Las 58 cepas de E. coli uropatógena presentan diversos perfiles de resistencia a quinolonas, siendo los más frecuentes con 43,10\% (25 cepas), las resistentes a ácido nalidíxico, ciprofloxacino, levofloxacino, norfloxacino y moxifloxacino. En el 86,20\% (50) de cepas se determinó, mediante RFLP-PCR, una mutación puntual en el gen gyr $A$ que cambió Ser 83 por Leu. La secuenciación de este gen, en 26 cepas de E. coli uropatógena resistentes a quinolonas, permitió detectar 23 cepas con mutaciones puntuales que cambian Ser 83 por Leu y 22 cepas que modifican Asp 87 por Asn; tres cepas no presentaron mutaciones.

\section{REFERENCIAS BIBLIOGRÁFICAS}

1. Foxman B, Barlow R, D’Arcy H, Gillespie B, Sobel JD. Urinary tract infection: self reported incidence and associated costs. Ann Epidemiol 2000; 10(8): 509-15.

2. Dezell JE, Lefevre ML. Urinary tract infections during pregnancy. Am Fam Physician 2000; 61(3): 713-21.

3. Foxman B. Epidemiology of urinary tract infections: incidence, morbidity, and economic costs. Am J Med 2002; 113 (Suppl 1A): $5 \mathrm{~S}-13 \mathrm{~S}$.

4. Alós JI, Serrano MG, Gómez- Garcés JL, Perianes J. Antibiotic resistance of Escherichia coli from communityacquired urinary tract infections in relation to demographic and clinical data. Clin Microbiol Infect 2005; 11(3): 199-203.

5. Stamm WE. An epidemic of urinary tract infections?. N Engl J Med 2001; 345 (14): 1055-7.

6. Kucheria R, Dasgupta P, Sacks SH, Khan MS, Sherrin N. Urinary tract infections: new insights into a common problem. Postgrad Med J 2005; 81(952): 83-86.

7. Leyva S, Leyva E. Fluoroquinolonas. Mecanismos de acción y resistencia, estructura, síntesis y reacciones fisicoquímicas importantes para propiedades medicinales. Bol. Sociedad Química México 2008; 2 (1): 1-13.
8. Chang TM, Lu PL, Li HH, Chang CY, Chen TC, Chang LL. Characterization of fluoroquinolone resistance mechanisms and their correlation with the degree of resistance to clinically used fluoroquinolones among Escherichia coli isolates. J Chemother 2007; 19(5): 488-94.

9. Alvarado O, Perfil microbiológico y resistencia bacteriana de infecciones del tracto urinario adquiridas en la comunidad en pacientes ambulatorios del hospital Nacional Daniel A. Carrión Callao - Perú. [Tesis para optar al título de Médico Cirujano] Facultad de Medicina Universidad Nacional Mayor de San Marcos, 2002.

10. Clinical and Laboratory Standards Institute. Methods for dilution antimicrobial susceptibility tests for bacteria that grow aerobically; approved standard-seventh edition. CLSI. Pennsylvania, 2006.

11. Gottesman BS, Carmeli Y, Shitrit $\mathrm{P}$ et al. Impact of quinolone restriction on resistance patterns of Escherichia coli isolated from urine by culture in a community setting. Clin Infect Dis 2009; 49(6): 869-75.

12. Guajardo-Lara CE, González-Martínez PM, Ayala-Gaytán JJ. Antibiotic resistance of Escherichia coli from communityacquired urinary tract infections. What antimicrobial to use?. Salud Publica Mex 2009; 51(2): 155 -9.

13. Conrad S, Oethinger M, Kaifel K, Klotz G, Marre R, Kern WV. gyr $A$ mutations in high-level fluoroquinoloneresistant clinical isolates of Escherichia coli. J Antimicrob Chemother 1996; 38: 443-455.

14. Simpson SA, Wood F, Butler CC. General practitioners' perceptions of antimicrobial resistance: a qualitative study. J Antimicrob Chemother 2007; 59(2): 292-6.

15. Guay DR. Contemporary management of uncomplicated urinary tract infections. Drugs 2008; 68(9): 1169-205.

16. Johnson JR, Johnston B, Clabots C, Kuskowski MA, Pendyala S, Debroy C y col. Escherichia coli sequence type ST131 as an emerging fluoroquinolone-resistant uropathogen among renal transplant recipients. Antimicrob Agents Chemother 2010; 54(1): 546-50.

17. Matute AJ, Hak E, Schurink CA, McArthur A, Alonso E, Paniagua $\mathrm{M}$, et al. Resistance of uropathogens in symptomatic urinary tract infections in León, Nicaragua. Int J Antimicrob Agents 2004; 23(5): 506-9.

18. Vila J, Ruiz J, Marco F, Barcelo AG, Giralt E, De Anta TJ. Association between double mutations in gyr $A$ gene of ciprofloxacin-resistant clinical isolates of Escherichia coliand MICs. Antimicrob Agents Chemother 1994; 38(10): 2477-79.

19. Chenia HY, Pillay B, Pillay D. Analysis of the mechanisms of fluoroquinolone resistance in urinary tract pathogens. J Antimicrob Chemother 2006; 58(6): 1274-8.

20. Hooper DC. Emerging mechanisms of fluoroquinolone resistance. Emerg Infect Dis 2001; 7(2): 337-41.

\section{Correspondencia}

Nombre: Mg. Ana María Horna Ruíz E-mail: $\quad$ anamariahornaruiz@hotmail.com 